\title{
Tegnologie en die mens
}

Brig D.F. Botha*

\begin{abstract}
People today live in a world of rapid technological change, that evolves from people themselves: change influences both individuals and organizations and the greater the implications and results of change - the greater the resistance to it. Organizations have to be aware of the tried behavioural science techniques and methods of handling change, in order to implement it successfully. This also includes the South African Defence Force.
\end{abstract}

\begin{abstract}
Verandering en veral tegnologiese verandering was nog altyd deel van menslike bestaan. Om mens te wees is om te ontdek, om te innoveer, om te skep en om daardeur sy omgewing te verander. Die mens het nog nooit by die natuur aangepas nie maar het voortdurend uit dit wat beskikbaar is die natuur verander om by die mens se behoeftes aan te pas. As die mens koud gekry het, het hy nie hare of pels gegroei nie maar het hy vir hom ' $n$ jas gemaak.
\end{abstract}

Hoewel dit aanvaar word dat verandering deel van die mens wees is, is die tempo waarteen dit plaasvind en die vooruitsig dat dit steeds vinniger en vinniger gaan wees, een van die mees aktuele onderwerpe van vandag. So vinnig is die versnelling dat om sin te maak van verandering, dit ons basiese industrie sal word. Dit word gestel dat die huidige, gekenmerk word deur talle rewolusionêre verandering tov tegnologie, kommunikasie, politiek, religie, moraliteit, wetenskap en die dimensies van ons samelewing.

Enkele voorbeelde wat die omvang van verandering oor die afgelope honderd jaar beklemtoon, is die volgende:

- Reisspoed en die vermoë om siekte te beheer het nagenoeg honderdvoudig verbeter.

- Die wêreldbevolking is ' $n$ duisendmaal groter.

- Die gebruik van energiebronne het tienduisendmaal verhoog.

- Die spoed van datahantering het nagenoeg met ' $n$ faktor van een miljoen verbeter terwyl die spoed van kommunikasie in dieselfde tyd met ' $n$ faktor van bykans tien miljoen verhoog is.

Dit word ook gestel dat die omvang van tegnologiese verandering oor die afgelope 20 jaar groter is as wat dit oor die afgelope 200000 jaar was. Op die wetenskaplike front word dit beweer dat die totale kennis elke tien jaar verdubbel en dat negentig persent van alle wetenskaplikes wat die wêreld nog opgelewer het vandag nog leef.
Teen hierdie agtergrond is dit gepas om ALWIN TOFFLER aan te haal wanneer hy sê:

"... that humanity is now a part of an environment so unfamiliar and complex that it is threatening millions with future shock! Future shock occurs when the types of change and the speed of introduction overpower the individual's ability to adapt. The problem comes not from a particular change that one cannot handle, but from the fact that since so many things are changing, new ways of dealing with the "temporary society" are needed. This temporary society is characterized by temporary housing, jobs, friendships, neighbourhoods, etc. Things move so quickly that there is no time for long-term stability, and values become a part of a "throw-away society".

\section{Tegnologie en tegnologiese verandering}

\section{Omskrywing en begripvorming}

Die vraag kan gevra word: Is tegnologie ' $n$ masjien, ' $n$ idee of ' $n$ konsep? Is dit ' $n$ uitvinding, ' $n$ wetenskap of ' $n$ filosofie? In ' $n$ baie eng verband kan tegnologie gelyk gestel word aan eenvoudige meganiese tegnieke terwyl in 'n baie breë verband daaraan gedink kan word as die totale kennisveld bekend aan die mens. Opsommend uit die beskikbare literatuur kan dit as volg gedefinieer word:

Tegnologie is die gereedskap, instrumente, masjinerie en tegniese formules wat tesame met die wetenskaplike veld van idees, kennis en ingenieursvernuf in geordende organisasies, met gebruikmaking van natuurlike hulpbronne en met inagneming van funksionele belangrikheid en tegniese prestasies, ten behoewe van die mens en sy omgewing aangewend word. 
In die geskiedenis van tegnologie word daar tussen verskeie fases onderskei. Alhoewel hierdie fases chronologies onderskeibaar is, en ook so ontwikkel het, is die skeidslyn tussen elke fase nie noodwendig eksak nie, en is daar van die vroeëre fases wat vandag nog bestaan. Die fases is kortliks die volgende:

- Hande-arbeid.

- Meganisasie. (Industriële rewolusie).

- Massaproduksie.

- Outomatisasie.

- Sybernesasie (Sybernetika - "Cybernetics"). Die term sybernetika word in breë verband gebruik om die algemene wetenskap van beheer oor komplekse stelsels, informasie en kommunikasies te omsluit. Sybernetika is die tegnologiese fase waar masjiene ander masjiene beheer, waar rekenaars, en nie mense nie die belangrike rol speel. Met sybernetika word mense, soos in die geval van outomatisasie, nie benodig om knoppies te druk en om meters dop te hou nie.

Seymour Wolfbein het die volgende breë areas, waar tegnologiese vooruitgang sy grootste impak gehad het, geïdentifiseer:

- Die landbou.

- Instrumentasie en outomatiese beheer.

- Numeriese beheer.

- Kommunikasie.

- Masjinerie en materiaalhantering.

- Vervoerwese.

- Kragopwekking.

Die grootste enkele gemene faktor in al hierdie areas was egter die impak wat die rekenaar gemaak het. Hieroor het HALL opgemerk:

"Whereas up to now technology has extended or even taken over what men do with their physical equipment - their hands and eyes and legs - with our generation for the first time the computer is providing brain power".

\section{Tegnologie en organisasie strukture}

In die verlede is tegnologie as ' $n$ faktor in organisasie teorie grootliks deur die gedragswetenskaplikes verwaarloos. Redelik onlangs (sestigerjare) met die WOODWARD - studies, opgevolg deur die ZWERMAN - bevindinge, is die besef tuisgebring dat tegnologie ' $n$ wesenlike, indien nie, die grootste impak, op organisasie teorie en analise het. JOAN WOODWARD het bevind dat tegnologie ' $n$ beduidende invloed op organisasie strukture, menslike verhoudinge en bestuurstelsels het. Soos LUTHANS dit stel:

"Up till the Woodward studies most theorists viewed the formal organization as being composed of a structure and possibly a group of processes. Technology was not considered as an integral part of the formal organization but, instead, was narrowly viewed as a set of limiting conditions. She felt that technology plays a role equal to, if not more important than, the roles of structure and processes".

\section{Die Woodward en Zwerman bevindinge kan kortliks as volg opgesom word:}

- Die organisatoriese eienskappe wat 'n direkte verband met tegnologiese vooruitgang getoon het was; die lengte van die bevelslyn, die spanwydte van beheer van die hoofbestuurder, die persentasie van totale omset wat toegewys word aan die betaling van lone en salarisse, die verhouding van bestuurders tot die totale personeel; van klerklike en administratiewe staf tot arbeiders; van direkte tot indirekte arbeid en van gegradueerde tot niegegradueerde personeel toesighoudend in produksie afdelings.

- Die tipe van produksie tegnologie het 'n baie nou en beduidende verband met veranderlikes in die organisatoriese eienskappe van ondernemings gehad.

- Tegnologie is egter nie die enigste belangrike veranderlike in die bepaling van organisasiestrukture nie. Daar is sekere definitiewe voorgeskrewe en funksionele verwantskappe tussen struktuur en tegnologiese vereistes.

\section{Tegno-strukture}

Met die besef van die belangrikheid van die invloei van tegnologie op organisasiestrukturering het nuwe modelle van organisasiestrukture te voorskyn gekom. Die sogenaamde, Projek-, Matrys-, Vrye-Vorm-en-Stelselstrukture is ontwerp om geredelik en effektief by veranderende en gevorderde tegnologie aan te pas.

\section{Die impak van rekenaars op organisasiestrukture}

Die ontwikkelings in die rekenaarwetenskap het as tegnologiese verandering seker die grootste enkele impak op die strukturering en prosesse- 
ring van organisasies gehad. Die tegnologiese deurbrake op die gebied van rekenaars het organisasies, volgens THOMAS WHISLER, as volg geraak:

- 'n Vermindering in die aantal halfgeskoolde en ongeskoolde werkers. 'n Gepaardgaande vermeerdering in hoogsgeskoolde werkers.

- 'n Konsolidasie van departemente en afdelings.

- 'n Vermindering van die aantal vlakke in die organisasie.

- 'n Krimping in die spanwydte van beheer.

- Die minimum van verandering in funksies soos, ingenieursontwerp, navorsing en ontwikkeling, industriële verhoudinge en bemarking.

- Grootskaalse veranderinge in funksies soos, produksie, ouditeuring en produkberging en verspreiding.

\section{Die gedrags-implikasies van moderne tegnologie}

Tegnologie en tegnologiese verandering het sekere definitiewe invloed op menslike gedrag en optrede. Hierdie invloed word voortdurend deur gedragswetenskaplikes bestudeer en hul bevindinge is in gedragswetenskaplike teorieë, geboekstaaf en geformuleer. Die gedragswetenskap is egter nie ' $n$ eksakte wetenskap soos die natuurwetenskap nie, daarom, vir die doeleindes van hierdie geskrif, word daar net in breë en pqpulêre terme na verskillende sienings verwys:

- Die Positiewe Siening. Tegnologie word gesien as die voertuig van alle vooruitgang. Dit hou die oplossing van al die mens se maatskaplike probleme in. Dit help om die indiwidu van die kloue van 'n komplekse en hoogs georganiseerde gemeenskap te bevry. Dit is die bron van permanente welvaart, of kortliks, die belofte van Utopia in ons tyd.

- Die Negatiewe Siening: Tegnologie het die totstandkoming van oneindig digte stedelike gemeenskappe tot gevolg gehad. Dit gaan gepaard met verlies aan indiwiduele privaatheid, die druk van die massas, en die standaardisasie van goedere en dienste. Die toenemende omgewingsbesoedeling, volgend op industrialisasie en verstedeliking, gee uiting tot krete van wanhoop en frustrasie. Die maatskaplike ontwrigting agv outomatisasie het die begrippe van vervreemding en naamloosheid op die voorgrond van sosiale bewustheid geplaas.

- Die Neutrale Siening. Tegnologie was nog nooit nuut nie, inteendeel, dit was sedert die Industriële Rewolusie nog altyd as 'n faktor van sosiale verandering beskou. Navorsing toon dat tegnologie nog weinig, sedert die 1880 's tot versnelde ekonomiese produktiwiteit, bygedra het. Daar word geredeneer dat tegnologiese verandering in die toekoms minder ontwrigtend as in die verlede gaan wees omdat die omvang en tempo daarvan, rofweg in balans met die mens se sosiale en psigologiese ontwikkeling is. Omdat tegnologie en tegnologiese verandering uiteraard uit die mens kom, sal die mens die tempo en die aard daarvan, inherent, beperk en vertraag tot die menslik aanvaarbare en beheerbare norme van sy era en omgewing. In teenstelling hiermee word daar geredeneer dat alhoewel daar beduidende getuienis is wat die "geen-effek" siening ondersteun, dit tog sekere onbetwisbare veranderlikes ignoreer. Blote fisiese krag, rekenarisering, spoed van kommunikasie, bevolkingsdigthede en ruimte eksplorasie is maar net ' $n$ paar veranderlikes wat maak dat moderne tegnologie, positief of negatief, 'n geweldige invloed op menslike gedrag, het.

- Die Media Siening. Die media siening kan as volg opgesom word: Die wêreld het die welvaart, die wetenskap, die tegnologie, en die energie om feitlik alles te doen wat hy behoort te doen of wil doen. Om so effektief en vinnig die apparatuur aaneen te skakel om 'n man op die maan te plaas is feitlik ongelooflik. Tog, volgens die New York Times:

"It has sickening racial problems, continuous wars, antique transport systems, horrible slums, shocking poverty, inadequate education systems, overloaded medical, mental and rehabilitation institutions, water unfit to drink and air so foul its largest cities may literally choke".

- 'n Algemene Siening. Uit die verskeeie sienings wat in die literatuur aangetref word is daar ook 'n deurlopende siening wat algemeen gehandhaaf word. Dit kom kortliks daarop neer dat die ernstige probleme wat die moderne samelewing van vandag teister, soos armoede, oorlog, ekologiese wanbalans en verslawingsmiddel misbruik, veroorsaak word deur tegnologie. Stemme gaan voortdurend op dat die wêreld en veral die groot wêreldmoondhede se prioriteite moet beweeg van die destruktiewe, (oorlog, ekologiese versteuring, verslawingsmiddele) na die konstruktiewe, (Welvaart, maatskaplikeen gesondheidsdienste), aanwending van die tegnologie. 
Vervreemding. Enige bespreking van die gedragsimplikasies van tegnologie moet noodwendig op die konsep van "vervreemding" fokus. Vervreemding het diverse betekenisse maar die konsep sluit gewoonlik een of meer van die volgende begrippe, in:

- Magteloosheid. Die tegnologiese stelsel stroop die mens van sy mag en laat hom vervreemd na, deurdat prerogatief en besluitneming, hom ontneem word.

- Sinloosheid. Die indiwidu kan nie die algehele betekenis van die tegnologie wat hom konfronteer begryp nie. Hy is onseker oor wat hy moet glo van tegnologie en hy soek voortdurend na betekenis. Dit lei tot ' $n$ lae verwagting dat toekomstige gevolg van gedrag nie bevredigend voorspel kan word nie.

- Normloosheid. Tegnologie word gesien as die oorsaak waarom die moderne mens al hoe meer die bestaande maatskaplike reëls en norme, in sy gemeenskap, verwerp.

- Isolasie. Tegnologie word genoem as die oorsaak waarom indiwidue afgetrokke en geïsoleerd teenoor 'n betrokke maatskaplike- en kulturele-omgewing begin staan. Die indiwidu ken 'n lae waarde toe, aan dit wat vir ander in sy omgewing, ' $n$ hoë waarde het.

- Self-ontvreemding. Tegnologie het ' $n$ toestand geskep waarin indiwidue nie meer intrinsieke bevredigende aktiwiteite kan vind nie.

\section{Verandering en weerstand teen verandering}

Verandering kan in drie kategorieë verdeel word, $\mathrm{nl}$ kulturele/maatskaplike-, organisatoriese- en tegnologiese-verandering. Daar is voortdurend ' $n$ wisselwerking tussen die drie, 'n verandering in die een het noodwendig ' $n$ invloed op die ander twee. Die vermoë van die meeste organisasies om by maatskaplike en kulturele verandering aan te pas is groter as hul vermoë om tegnologiese verandering te akkommodeer. Met die koms van die rekenaar, het kulturele weerstand, in baie gevalle, die sinvolle gebruik van hierdie nuwe tegnologie in organisasie, verhoed.

In hierdie verband sê TOFFLER:

"... the next few decades will bring about an avalanche of change and that most people and organizations are not prepared for the vastly accelerated pace of change."
Die areas van vinnig versnellende verandering (verandering in die algemeen en nie net tegnologies nie), word as die volgende gesien:

- Die kennis-, inligtings- en kommunikasie-ontploffings.

- Die vinnige tempo van produkveroudering

- Die veranderde samestelling van die arbeidsmag en werksgeleenthede. (Van produksie na dienste georiënteerd).

- Die groeiende bewustheid en kommer oor persoonlike en maatskaplike sake.

- Die toenemende internasionalisasie van ekonomiese bedrywighede.

Teen hierdie agtergrond is dit dus vir organisasies en indiwidue nodig om verandering te verstaan en om verandering te kan bestuur. Vier verskillende tipes van verandering en/of veranderingsagente is toepasbaar op die meeste organisasies:

- Eksterne druk, gerig op die totale organisasie, wat 'n wye reeks van taktiek behels en wat optrede soos massa demonstrasies en wetsverontagsaming insluit.

- Organisasie ontwikkeling, ook gerig op die totale organisasie en wat tegnieke soos spanbou, leierskapseminare, en konflikhantering, insluit.

- Mens verandering gerig tot indiwidue in die organisasie en wat hoofsaaklik bestuurs- en ander opleiding behels.

- Top bestuursanalise waar die klem op die boonste echelon van bestuur geplaas word om tegnologiese en strukturele veranderings te aanvaar.

Verandering word nie altyd geredelik deur groepe of indiwidue aanvaar nie. Dit gaan heel dikwels gepaard met groot weerstand, wat lei tot traumatiese en ontwrigtende gebeure binne organisasies. Weerstand teen verandering ("The $\mathrm{RC}$-factor") is 'n onderwerp wat deeglik deur gedragswetenskaplikes bestudeer is en waaroor daar heelwat geskryf is. 'n Magdom van empiriese navorsing, wat gelei het tot uiteenlopende teorieë, is in hierdie verband gedoen. Die bestek van hierdie geskrif laat dit nie toe om alle teorieë tov verandering en weerstand teen verandering te bespreek nie, derhalwe sal daar na net ' $n$ paar belangrikes verwys word.

Navorsing het byvoorbeeld getoon dat weerstand teen verandering direk eweredig is aan ouderdom. Maw hoe ouer die mens word, hoe groter weerstand bied hy teen verandering. Nog ' $n$ teorie konstateer dat weerstand teen verande- 
ring indirek eweredig is aan intelligensie. Hoe intelligenter die mens hoe minder weerstand bied hy teen verandering. Navorsing het verder getoon dat weerstand teen verandering direk eweredig is aan die gevolge van verandering. As dit die persepsie is dat die gevolge van die verandering drasties gaan wees sal die weerstand baie groot wees. (Die navorsing wat gelei het tot hierdie teorieë is gedoen onder streng laboratoriumbeheerde toestande waar afhanklike veranderlikes tot 'n minimum beperk was).

Hellriegel en Slocum vat egter verskeie teorieë saam wanneer hulle sê daar 'n indiwiduele en organisasie weerstandsproses is en dat organisatoriese verandering slegs teweeg gebring kan word indien bestuur hierdie prosesse kan herken en verstaan. Die indiwiduele weerstandsproses word gekenmerk deur kragte soos gewoonte, selektiewe persepsie, afhanklikheid, onsekerheid en regressie, wat op die indiwidu inwerk. Die kragte wat op die organisasie in die organisasie weerstandsproses inwerk, is, stabiliteit van die stelsel, hulpbronbeperkings, versonke koste en interorganisatoriese ooreenkomste. Genoemde skrywers erken dat daar ook verskeie ander redes is waarom mense en organisasies verandering teenstaan, waarom verandering nie deur mense en organisasies onderneem word nie en waarom daar swak prestasie is nadat verandering geïmplimenteer is.

Edgar Huse het in wat hy noem sy "Principles of Change" verskeie faktore onderskei wat die weerstand teen verandering in indiwidue en organisasies sal verhoog. Weerstand sal verhoog as verandering gesien word as ' $n$ bedreiging, hetsy vir 'n indiwidu, 'n toesighouer, 'n groep of 'n organisasie. Verder sal enige verandering gewoonlik teengestaan word deur die betrokke indiwidu, toesighouer of groep indien hulle nie geraadpleeg en/of deelgemaak is van die beoogde verandering nie.

\section{Huse se faktore wat weerstand teen verande- ring kan verhoog is oa die volgende:}

- Die indiwidu moet 'n persoonlike voordeel in die verandering sien voordat hy gewilliglik aan die veranderingsproses sal deelneem.

- Hoe groter die prestige van die leier (formele of informele) hoe groter is die invloed wat hy op die groep tot voordeel vir verandering kan uitoefen.

- Sterk druk vir verandering kan gevestig word indien 'n groep met spesifieke en verlangde inligting oor hulself en hul gedrag, voorsien word.

- Sterk druk vir verandering kan gevestig word in groepslede indien hulle die persepsie het dat die behoefte vir verandering vanuit hulself kom.

- Die weerstand teen verandering kan verlaag word indien die mens wat verander moet word en daardie wat invloed om te verander, moet uitoefen, 'n sterk gevoel het dat hulle lede van dieselfde groep is.

- Inligting wat verwys na die behoefte vir verandering, planne vir verandering en die gevolge van verandering moet deur alle betrokke en relevante lede van die groep gedeel word.

Die gevolge van weerstand teen verandering is 'n verdere faktor wat in ag geneem moet word by die implementering van verandering. Weerstand teen verandering kan gemanifesteer word in overte of implisiete defensiewe gedrag. Overte defensiewe gedrag kan bv in die vorm van stakings, vakbonding, vertragings en sabotasie; voorkom. Implisiete defensiewe gedrag kan herken word aan dinge soos, verlies van lojaliteit teenoor die organisasie, verlies aan motivering om te werk, toenemende foute, toenemende afwesigheid, ens. Overte of implisiete weerstand kan onmiddellik of by latere geleenthede plaasvind. In baie gevalle sal onmiddellike reaksie baie gering wees en sal 'n hele aantal veranderings moet plaasvind voordat dit na eskalerende aksies sal lei.

\section{Die implementering van verandering}

$\mathrm{Na}$ 'n intensiewe literatuurstudie deur Greiner het hy die sewe mees algemene en gebruikte benaderings tot die implementering van verandering, as volg, in rangorde van magsverspreiding, geïdentifiseer:

- Die Dekreetbenadering. Dit kom van bo-af en word deur die organisasie met "een-rigting" kommunikasie, na onder, deurgegee.

- Die Vervangingsbenadering. Die aanname hier is dat organisatoriese verandering teweeggebring kan word deur personeel en veral sleutelpersoneel, te vervang, te verplaas of te bevorder.

- Die Strukturele benadering. Met hierdie benadering word verandering teweeggebring deur die struktuur van die organisasie te verander. Die hiërargiese verwantskap van toesighouers en ondergeskiktes word beïnvloed.

- Die Groepbesluit benadering. Dit behels die deelname van groepslede in die selektering 
en implementering van alternatiewe wat deur ander gespesifiseer is. Ander identifiseer die probleem: die groep kom ooreen op 'n plan van aksie, gekies uit die beskikbare alternatiewe.

- Die Databesprekingsbenadering. Met behulp van 'n eksterne veranderingsagent maak organisasielede hul eie analise van beskikbare data om probleme te identifiseer en veranderings in te stel

\section{- Die Groep probleemoplossingsbenade-} ring. Hierdie benadering verskil van die vorige een deurdat die groep nou ook, met behulp van die eksterne agent, hulle eie data, vir probleem identifisering en veranderingsimplementering, genereer.

- Die T-Groep benadering. Hier word die groep opgelei om die prosesse van indiwiduele- en groepsgedrag te verstaan. Hierdie benadering fokus op interpersoonlike verwantskappe en werk dan na die verbetering van werksprestasie.

In die woorde van Edgar Huse kan hierdie benaderings tov magsverspreiding as volg beskryf word.

"As can be seen these approaches follow a roughly descending order from unilateral power, to collaborative power, through shared influence as represented by the $T$ group."

In enige stabiele organisasie bestaan daar ' $n$ kragveld wat in balans gehou word deur kragte wat verandering teenstaan en kragte wat verandering voorstaan. Hierdie kragte bestaan intern tot die organisasie en die organisasie word beskou om in 'n kwasi-statiese balans te wees. Verandering, agv eksterne of interne kragte, is daarop gemik om hierdie balanspunt te verskuif en om so 'n verskuiwing met die minste moontlike ontwrigting te bewerkstellig. Indien die kragte wat verandering voorstaan té drasties toegepas word is die teenreaksie gewoonlik heftig en kan dit lei tot ongewenste konflik. Alle skrywers is dit eens dat daar by organisatoriese verandering gestreef moet word om die kragte teen verandering te verminder eerder as om die kragte vir verandering te verhoog.

Om dus veranderings in organisasies in te stel is dit nodig, om wat genoem word, 'n kragveldanalise te maak. Alhoewel die kragte betrokke by organisasies nie soos in die natuurwetenskappe gekwantifiseer kan word nie, is 'n blote diagrammatisering van kragte, vir en teen veran-

dering, alreeds 'n groot hulpmiddel om probleemareas te identifiseer.

Lewin beskryf verandering as 'n drie-stap prosedure waar die organisasie eers ontvries word, dan beweeg word en uiteindelik weer bevries word. Die ontvriesingsproses beteken gewoonlik dat die kragte wat die organisasie op sy huidige vlak hou, verminder moet word. Ontvriesing kan verkry word deur bv inligting aan indiwidue of groepe in die organisasie vry te stel en te kommunikeer, wat sal meehelp dat hierdie teikengroepe self tot ' $n$ besluit sal kom dat verandering wel nodig is. Vervolgens word die organisasie na die gewensde nuwe vlak beweeg. Hierdie stap behels gewoonlik die ontwikkeling van nuwe waardes, gedrag of houding deur erkenning, identifikasie of struktuurverandering. Die derde stap in die veranderingsproses, $\mathrm{nl}$ bevriesing, behels die stabilisering van die verandering op die nuwe vlak deur gebruik te maak van ondersteuningsmeganismes soos verandering in organisasie kultuur, veranderings in groepsnorme en/of modifisering van organisasiebeleid.

Die model van Lewin is later vergroot deurdat 'n veranderingsagent bygevoeg is om met die proses te help. Twee addisionele stappe moes dus bykom. Die vyfstap model sien as volg daaruit:

Stap 1 Ontwikkel die behoefte om te verander. (ontvriesing).

Stap 2 Vestiging van 'n veranderingsverwantskap.

Stap 3 Werk in die rigting van verandering. (Beweging).

Stap 4 Veralgemening en stabilisering van verandering. (Bevriesing).

Stap 5 Verkry 'n terminale verwantskap.

Hellriegel en Slocum beweer dat daar in organisasies ' $n$ voortdurende wisselwerking is tussen die kragte van taak, tegnologie, mense en struktuur en dat daar vir elkeen van hierdie kragte spesifieke veranderingstrategieë ontwikkel moet word. Die volgende word as voorbeeld genoem.

$\begin{array}{ll}\text { KRAGTE } & \text { VERANDERINGSTRATEGIE } \\ \text { Taak } & \text { Modifiseer aard van taak. } \\ & \begin{array}{l}\text { Herontwerp werk } \\ \text { Span ontwikkeling }\end{array} \\ \text { Tegnologie } & \begin{array}{l}\text { Modifiseer produksiemetodes. } \\ \text { Modifiseer masjinerie. } \\ \\ \text { Outomatisasie. }\end{array}\end{array}$




\author{
Mense Op-taak opleiding. \\ Bestuursontwikkelingspro- \\ gramme. \\ Organisasie-ontwikkelingspro- \\ gramme. wings.
Verander organisasie verant- woordelikheidstruktuur.
Verander organisasiestruktuur. \\ Struktuur Verander pos/werksbeskry-
}

Alternatiewe benaderings om verandering in organisasies te implementeer word ook deur Porter, Lawler en Hackman gepropageer. Die volgende drie is die belangrikste.

- Die verandering van indiwidue wat in die organisasie werk. Dit kan geskied deur keuring, bevorderings, afdankings, opleiding, ontwikkeling en die verandering van indiwiduele motiewe.

- Die verandering van organisasiestrukture en stelsels. Hier moet na die anatomiese dimensie soos vorm en grootte, desentralisasie en spesialisasie gekyk word. Verder moet daar ook op die operasionele kenmerke, soos verantwoordelikheid- en werkstrukture, tegniese-, beheer-, vergoeding- en merietestelsels gelet word.

- Die direkte verandering van organisasie klimaat en interpersoonlike styl. Dit kan bewerkstellig word dmv beplande ingrepe soos spanbou, aksie beplanning, organisasie ontwikkeling ("OD"), proses konsultasie, interpersoonlike intervensie, konflik hantering, en laboratorium oefeninge.

Organisasie-ontwikkeling. (OO). Organisasie ontwikkeling is 'n nuwe opkomende dissipline wat daarop gerig is om verandering te kan hanteer en te kan bestuur deur van toegepaste gedragswetenskaplike kennis, gebruik te maak. Dit is een van die vele benaderings tot verandering, maar dit is een wat daarna streef om menslike sowel as organisasiehulpbronne te optimaliseer. Organisasie-ontwikkeling is ' $n$ totale benadering, wat alle aspekte van indiwiduele-, groeps- en organisasiegedrag bestudeer om verandering en weerstand teen verandering in die menslike- en organisatoriese-omgewing, te kan hanteer.

Sommige van die tegnieke, vir die implementering van verandering, soos hierbo bespreek, word $\mathrm{OO}$ intervensies, genoem. Dit is, maw, ingrepe wat in die organisasie en sy mense gemaak word met die doel om verandering, dmv ' $n$ gedragswetenskaplike benadering, teweeg te bring. Om hierdie intervensies te beheer word gewoonlik van eksterne veranderingsagente gebruik gemaak. Dit is hoofsaaklik bestuurskonsultante wat in die organisasie se diens is, of dit kan ook gekontrakteerde professionele gedragswetenskaplikes wees.

Van die tegnieke/benaderings wat hierdie gedragswetenskaplike bestuurskonsultasie vir OO intervensies gebruik is oa die volgende:

- Werksverwagtingstegniek ("Job Expectation Technique-JET).

- Werksverryking ("Job Enrichment").

- Doelwitbestuur.

- Besluitnemingsentrums.

- Proseskonsultasie.

- Spanbou.

- Laboratorium opleiding.

- Gedragsverandering. (Baie gevaarlik as dit nie deur die regte persoon gedoen word nie).

- Transaksie-analise.

- Die "Gestalt" benadering.

- Menslike hulpbron ouditering.

- Aksie-profielmeting.

Dit is duidelik uit die literatuur dat 'n magdom nuwe tegnieke/benaderings in die $\mathrm{OO}$ veld beskikbaar is, en deur organisasies en konsultante gebruik word. Soos deur Edgar Huse gestel.

"Since the art has developed faster than the applied research, not all practitioners would agree that the different types of interventions used today are actually $O D$ interventions."

Omdat $\mathrm{OO}$ nog ' $\mathrm{n}$ redelike onontwikkelde veld in die gedragswetenskappe is moet organisasies daarteen waak om nie sommer enige, nuwe gepakketeerde tegniek, wat op die mark verskyn, aan te gryp nie. Dit gaan nie altyd die alfa en omega tot die oplossing van veranderingsprobleme in die organisasie wees nie. Nie een tegniek/benadering is by uitstek geskik vir alle organisasie probleme of situasies nie. Organisasiekultuur, struktuur en/of omstandighede sal aandui watter tegniek/benadering of kombinasie van tegnieke en/of benaderings geskik gaan wees. Dat $\mathrm{OO}$ tegnieke/benaderings vir die implementering van verandering wel nodig is, word geensins betwyfel nie, in teendeel, in die moderne tegnologiese omgewing word dit as noodsaaklik beskou. 


\section{Slotsom}

Die mens lewe in 'n wêreld van snelle tegnologiese verandering, verandering wat uit die mens self kom. Die mensdom is in organisasievorme en -strukture, georganiseer. Verandering het op indiwidue sowel as organisasies ' $n$ impak. Die aard en omvang van die verandering word gereflekteer in die betrokke mens en organisasie se vermoë om dit te kan hanteer. Hoe groter die implikasies en gevolge van die verandering, hoe groter die weerstand. Om weerstand teen verandering te negeer is dit nodig om indiwidue en organisasies, dmv beproefde gedragswetenskaplike tegnieke en metodes, te ontwikkel. Organisasies moet van hierdie tegnieke/metode om verandering te kan hanteer, bewus wees en moet bereid wees om dit doelgerig toe te pas en te eksploiteer. Selfs die Suid-Afrikaanse Weermag is nie hierby uitgesluit nie.

*Brig. D.F. Botha PR ING BSCB ING, MBA.

\section{BIBLIOGRAFIE}

Boeke

1. French, Wendell, L. en Bell, Cecil, H. Organization Development. Prentice Hall, New Jersey. 1978

2. Hellriegel, Don en Slocum, John, W. Management: Contingency Approach. Addison-Wesley. Reading - Massachusetts. 1978.

3. Huse, Edgar, F. Organizational Development and Change. West Publishing Co. St. Paul. New York. 1976.

4. Jones, Barry. Sleepers, Wake! Technology and the Future of Work Wheatsheat Books Ltd. 1982.

5. Patten, Thomas, H. Classics of personnel Management. Moore Publishing Co. Oak Illinois. 1979.

6. Porter, Lyman W, Lawler, Edward E. and Hackman, Richard J. Behaviour in Organizations. McGraw-Hill, Kogakusha, Ltd. 1975.

7. Toffler, Alvin. The Third Wave. Collin. 1980.

\section{Artikels}

8. Burgess, E.A. The new Technology. The Journal of the Royal Artillery. Vol. C VI. No. 1. 1979.

9. Morison, Elting, E. A Case study of Innovation. Engineering and Science Monthly. April 1960.

10. Bourke, John, E. Force Modernization. Military Review. April 1983.

11. Stethem, Nickolas. Human Factors in Modern War.

12. Seidenman, Paul. Human Engineering. National Defence. Vol. 66, №. 374, 1982. 